\title{
Epidemiological transition of tropical diseases in the Brazilian Amazon
}

\author{
Marcus Vinícius Guimarães Lacerda ${ }^{[1],[2]}$ and Gustavo Adolfo Sierra Romero ${ }^{[3]}$
}

[1]. Fundação de Medicina Tropical Dr. Heitor Vieira Dourado, Manaus, AM. [2]. Instituto de Pesquisa Leônidas \& Maria Deane, Fundação Oswaldo Cruz, Manaus, AM. [3]. Núcleo de Medicina Tropical, Universidade de Brasília, Brasília, DF.

Brazil has been a pioneer in the study of tropical diseases from the time it was a Portuguese colony and engaged in slave trading with Africa. The Escola Tropicalista Baiana in the $19^{\text {th }}$ century systematized the knowledge of these diseases, providing a strong foundation for subsequent studies ${ }^{(1)}$. In Brazil, the prolonged polarized model of the epidemiological transition common to most Latin American countries ${ }^{(2)}$, has affected mainly the North of the country as the center of most endemic tropical illnesses, mostly due to its warmer/tropical climate, favorable to vectors involved in transmission of several of these diseases. However, even in the Brazilian Amazon, improvements in public health associated with the ongoing implementation of a universal health system $^{(3)}$, combined with benefits associated with governmental cash transfer programs contribute to drastic changes in the profiles of most prevalent diseases ${ }^{(4)(5)}$.

The current special issue of the Revista da Sociedade Brasileira de Medicina Tropical/Journal of the Brazilian Society of Tropical Medicine focuses on infectious diseases in the Amazon, mainly the Amazonas State. In this region, the Fundação de Medicina Tropical Dr. Heitor Vieira Dourado, founded in 1974, has been influential in several fronts including: 1) building qualified health centers for providing treatment and carrying out surveillance, 2) conducting research to fill knowledge gaps, and 3 ) training graduate and postgraduate students, clinical staff and public health officers to improve health services and research on infectious and parasitic diseases in the region.

The Amazon region is undergoing a transition in which the incidence of classic illnesses such as malaria, Hansen and waterborne diseases has decreased, but new health concerns such as human immunodeficiency virus (HIV) are emerging as important public health problems. Other diseases and conditions are simultaneously overlooked, as their associated morbidity affects only the most neglected populations, such as the case of snake bites and other venomous animals. Diseases of higher

Corresponding author: Dr. Marcus Vinícius Guimarães de Lacerda. Diretoria de Ensino e Pesquisa/Fundação de Medicina Tropical Dr. Heitor Vieira Dourado. Av. Pedro Teixeira 25, Dom Pedro, 69.040-000 Manaus, AM, Brasil.

Phone: 5592 2127-3430

e-mail: marcuslacerda.br@gmail.com

Received 11 May 2015

Accepted 12 May 2015 incidence in the past have re-emerged in large numbers as is the case of dengue fever, while others such as acute Chagas' disease acquired by oral transmission remains prevalent in the region. The spread of HIV infection imposes an additional challenge to the health system as there is a need to address coinfections including mainly tuberculosis, leishmaniasis, Chagas disease and viral hepatitis. In this dynamic scenario where old and new diseases coexist in a population increasingly more urbanized and mobile, the accumulated regional knowledge on the epidemiology of infections becomes crucially relevant and of strategic importance to contribute to an upgrading of prevention and control measures. Then, prioritization of and investment in research activities that address key questions in this area are urgently needed.

In this issue, Sampaio et al. ${ }^{(6)}$ offer a historical view on the behavior of malaria associated with cycles of economic development in the Amazon region, an essential step in the path towards planning the elimination of Plasmodium falciparum infection ${ }^{(6)}$. As a result of a very successful control program, there has been a considerable reduction in the number of falciparum malaria cases which has led national policy makers to discuss elimination at national level. This represents a major paradigm shift which clearly reflects the epidemiological transition currently occurring not only in Brazil, but also in other tropical areas ${ }^{(7)}$.

Guerra et al.$^{(8)}$ in a long historical series on the seasonal behavior of leishmaniasis which included at least one major epidemic, demonstrate the vulnerability of the Amazonas state's population to an illness that is also linked to activities related to the use and exploitation of the environment and highlights the need to identify strategies for prevention of this disease ${ }^{(8)}$.

Mourão et al ${ }^{(9)}$ have reviewed arboviruses in the western Amazon, the diversity of etiologic agents and the advantages of implementing a syndromic approach in health care services for the proper construction of an efficient surveillance system ${ }^{(9)}$.

The review of Barbosa et al. ${ }^{(10)}$ draws attention to the relevance of indigenous transmission of Chagas disease in the Amazon, highlighting the importance of focusing research on parasite and vector diversity for a better understanding of the clinical behavior of the disease in the region and transmission cycles that are relevant to human health ${ }^{(10)}$. 
The review by Feitosa et al. ${ }^{(11)}$ systematically addresses snake bites as one of the most neglected problems in the Amazon region. This review demonstrates the magnitude of this type of envenoming in a background of lack of information, calling for a more aggressive approach by the authorities and affected communities to implement an appropriate surveillance system and promote the reduction of risk in the affected populations as well as ensuring access to timely treatment. Despite the low mortality registered, the sequelae of severe poisoning are important and timely treatment would reduce both harmful sequelae and mortality ${ }^{(11)}$.

A comprehensive review by Martins et al. ${ }^{(12)}$ regarding waterborne diseases shows a cholera record in the State of Amazonas and historical data that demonstrate that the incidence of diseases such as typhoid fever and amoebic liver abscess has declined considerably, whereas the risk of other diseases including leptospirosis has increased as a consequence of unplanned occupation of urban spaces that make them vulnerable to flooding ${ }^{(12)}$.

Cunha et al. ${ }^{(13)}$ discuss Hansen disease in the State of Amazonas and demonstrate a reduction in its incidence associated with decentralization of healthcare delivery by the national control program. The authors point out the dilemma faced by a region where new cases are now very rare, but there is a need to expand the coverage of dermatological examination to improve detection as well to maintain the accumulated experience of highly qualified institutions such as the Alfredo da Matta Foundation in Manaus ${ }^{(13)}$.

Tuberculosis remains a major challenge in the region and the historical series analyzed by Garrido et al. ${ }^{(14)}$ clearly shows a high mortality rate and a poor performance of the indicators of treatment success, which are affected by specific problems faced by the indigenous population and the growing human immunodeficiency virus/acquired immunodeficiency syndrome (HIV/AIDS) epidemic of. The main concern is the emergence of multidrug resistant $M$. tuberculosis, especially considering the frequent lack of access to timely diagnosis coupled with a high rate of noncompliance with treatment ${ }^{(14)}$.

Trends and challenges of HIV/AIDS in the State of Amazonas are analyzed by Oliveira et al. ${ }^{(15)}$ to reveal a worrying scenario characterized by the epidemic in regions where the socio-economic conditions, the quality and quantity of health services, as well as access to services are real obstacles to the full implementation of control program actions. Attention should focus on a possible imminent emergence of syndromes associated with co-infections with pathogens prevalent in the Amazon scenario. HIV/AIDS is currently the fastest growing disease in the North of Brazil, with similar endemic features to the 1980s including late diagnosis and high frequency of opportunistic infections because of non-adherence to antiretroviral therapy ${ }^{(15)}$.

Finally, the historical series analyzed by Saraiva et al. ${ }^{(16)}$ shows the changes in the etiologic profile of meningitis over the past decades in the State of Amazonas, evidencing the impact of the introduction of the Haemophilus influenzae vaccine and the emergence of serogroup C Neisseria meningitidis as well as Cryptococcus neoformans associated with HIV/AIDS.
It is striking that the overall mortality rates due to meningitis remain high, which could be probably reduced by implementing strategies such as qualification of health services for early detection, timely treatment and the implementation of relevant preventive measures ${ }^{(16)}$.

The history of tropical medicine in Brazil is intertwined with the history of treatment and research institutions in this area. Therefore, one can trace the evolution of regional major tropical endemic diseases by data recorded by these institutions. The importance of strengthening research and training of qualified staff locally where the most neglected populations live is underscored in this supplement. In a country of continental dimensions such as Brazil, priorities regarding investment in resources should be redirected to definitely solve the existing regional inequalities that are typical of the current polarized epidemiological transition model.

\section{CONFLICT OF INTEREST}

The authors declare that there is no conflict of interest.

\section{REFERENCES}

1. Prata A. Comemoração do centenário da descoberta do Schistosoma mansoni no Brasil. Rev Soc Bras Med Trop 2008; 41:689-691.

2. Frenk J, Frejka T, Bobadilla JL, Stern C, Lozano R, Sepúlveda J, et al. The epidemiologic transition in Latin America. Bol Oficina Sanit Panam 1991; 111:485-496.

3. Atun R, de Andrade LO, Almeida G, Cotlear D, Dmytraczenko T, Frenz P, et al. Health-system reform and universal health coverage in Latin America. Lancet 2015; 385:1230-1247.

4. Rasella D, Aquino R, Santos CA, Paes-Sousa R, Barreto ML. Effect of a conditional cash transfer programme on childhood mortality: a nationwide analysis of Brazilian municipalities. Lancet 2013; 382:57-64.

5. Nery JS, Pereira SM, Rasella D, Penna ML, Aquino R, Rodrigues LC, et al. Effect of the Brazilian conditional cash transfer and primary health care programs on the new case detection rate of leprosy. PLoS Neg1 Trop Dis 2014; 8:e3357.

6. Sampaio VS, Siqueira AM, Alecrim MGC, Mourão MPG, Marchesini PB, Albuquerque C, et al. Malaria in the State of Amazonas: a typical Brasilian tropical disease influenced by waves of economic development. Rev Soc Bras Med Trop 2015; 48 (Suppl I):4-11

7. González-Silva M, Bassat Q, Alonso PL. Getting ready for malaria elimination: a check list of critical issues to consider. Mem Inst Oswaldo Cruz 2014; 109:517-521.

8. Guerra JAO, Maciel MG, Guerra MVF, Talhari AC, Prestes SR, Fernandes MA, et al. Tegumentary leishmaniasis in the State of Amazonas: what have we learned and what do we need? Rev Soc Bras Med Trop 2015; 48 (Suppl I):12-19.

9. Mourão MPG, Bastos MS, Figueiredo RMP, Gimaque JBL, Alves VCR, Saraiva MGG, et al. Arboviral diseases in the Western Brazilian Amazon: a perspective and analysis from a tertiary health \& research center in Manaus, State of Amazonas. Rev Soc Bras Med Trop 2015; 48 (Suppl I):20-26.

10. Barbosa MGV, Ferreira JMBB, Arcanjo ARL, Santana RAG, Magalhães LKC, Magalhães LKC, et al. Chagas disease in the State of Amazonas: history, epidemiological evolution, risks of 
endemicity and future perspectives. Rev Soc Bras Med Trop 2015; 48 (Suppl I):27-33.

11. Feitosa ES, Sampaio V, Sachett J, Castro DB, Noronha MDN, Lazano JLL, et al. Snakebites as a largely neglected problem in the Brazilian Amazon: highlights of the epidemiological trends in the State of Amazonas. Rev Soc Bras Med Trop 2015; 48 (Suppl I):34-41.

12. Martins M, Lacerda MVG, Monteiro WM, Moura MAS, Santos ECS, Saraceni V, et al. Progression of the load of waterborne and intestinal parasitic diseases in the State of Amazonas. Rev Soc Bras Med Trop 2015; 48 (Suppl I):52-54.

13. Cunha C, Pedrosa VL, Dias LC, Braga A, Chrusciak-Talhari A, Santos M, et al. A historical overview of leprosy epidemiology and control activities in Amazonas, Brazil. Rev Soc Bras Med Trop 2015; 48 (Suppl I):55-62.

14. Garrido MS, Büher-Sékula S, Souza AB, Ramasawmy R, Quincó PL, Monte RL, et al. Temporal distribution of tuberculosis in the State of Amazonas, Brazil. Rev Soc Bras Med Trop 2015; 48 (Suppl I):63-69.

15. Oliveira RS, Benzaken AS, Saraceni V, Sabidó M. HIV/AIDS epidemic in the State of Amazonas: characteristics and trends from 2001 to 2012. Rev Soc Bras Med Trop 2015; 48 (Suppl I):70-78.

16. Saraiva MGG, Santos ECS, Saraceni V, Rocha LLS, Monte RL, Albuquerque $\mathrm{BC}$, et al. Epidemiology of infectious meningitis in the State of Amazonas, Brazil. Rev Soc Bras Med Trop 2015; 48 (Suppl I):79-86. 